\title{
What are journals for?
}

'The secret is comprised in three words - work, finish, publish.'

Michael Faraday

There are many reasons doctors want to publish their work. For most at an early stage in their career, this may be to add a line to their curriculum vitae and advance their careers but for academics, publishing is an expectation. Many will believe they have something important to say, and wish to provoke debate and discussion; others wish to share knowledge and experiences, which in medicine can lead to a satisfying change in clinical practice. All serve to register one's idea and educate others. However, for some, the reason is as basic as money. As we celebrate the 350th anniversary of the first academic publication, perhaps we have come full circle when it comes to why people publish?

Publishing is a flourishing business. There were approximately 28,100 active scholarly peer-reviewed journals in mid-2012 collectively publishing about 1.8-1.9 million articles per year. The number of articles published each year and the number of journals have both grown steadily for more than two centuries, by about $3 \%$ and $3.5 \%$ per year respectively. ${ }^{1}$

Journals have a responsibility to refine and define information and act as a scientific filter. Many of us will receive daily invitations in our email inbox from eclectic and new journals that are likely to take anything - is the filter now too porous? But this industry is like any other commercial activity and the supply still far outstrips the demand. Perhaps the internet revolution has merely fuelled our hunger to publish more?

The launch of this exciting and innovative series about publishing coincides with the 350th celebration of the publication of the first academic journal. In the age of social media, the first question is 'What are journals for?', which Simon Rallison sets out to answer. Simon is Director of Publications at the Physiological Society, and was previously a journal publisher with Earthscan, Springer and Blackwell.

Writing is hard work and, through this series, I hope the reader will get some useful insight into this service industry for academia.

\section{JYOTI SHAH}

Commissioning Editor

\section{Reference}

Ware M, Mabe M. The STM Report. 3rd edn. The Hague: International Association of Scientific, Technical and Medical Publishers; 2012.

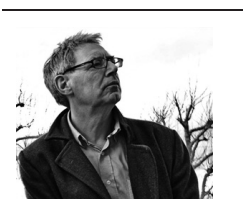

\section{SP Rallison}

Director of Publications, Physiological Society, UK

CORRESPONDENCE TO

Simon Rallison, E: srallison@physoc.org

In an age of the internet and social media, why are we still using (admittedly with refinements and improvements) a form of publication dating from 1665? What exactly is a journal in the 21 st century and what role does it have to perform? Surprisingly, the academic journal has not evolved since it was invented 350 years ago. ${ }^{1}$ The first issue of the Philosophical Transactions of the Royal Society was published in 1665, the brainchild of Henry Oldenburg and Robert Hooke. Since then, journals have digitised and now offer greater opportunity for research communication - but are authors taking advantage of what journals can offer? The academic and research community is generally very conservative about what it reads and how it views journals. There are, however, also frequent misunderstandings about the operation of journals. 


\section{What does a journal have to do?}

The table of contents of the first issue of the Philosophical Transactions of the Royal Society (of which Oldenburg was both editor and publisher) will sound familiar to modern journal readers: nine articles, a dedication, a list of books and other correspondence. Little has changed since then. It is noteworthy that, as long ago as 1665, Oldenburg and Hooke understood that the journal had to perform the following four functions if it was to meet the needs of both author and reader:

1. Registration of the author's claim to the work - authors want recognition that they got there first

2. Certification, usually by peer review, that the research was conducted properly - readers need to trust what they are reading and authors want their claims accepted

3. Dissemination - authors want to reach the right audience and readers want access

4. Archiving - both the author and reader want a permanent public record of the work that can be found and cited

As journals proliferate, a fifth function could be added to Oldenburg's list:

5. Navigation - readers need signposts and systems that help them find the articles they want to read

In practice, journals must also be affordable and publish in a timely manner to be of any use.

\section{What more can journals provide?}

Journal publishers deserve credit for extensively experimenting with and investing in digitisation and delivery platforms before there was a market for electronic journals. Consequently, they avoided the fate of the book and music industries, where 'content providers' have been squeezed by technology companies like Amazon and Apple. As a result, we have a diverse landscape of large and small publishers and journals. The journals provide different niches for the communication of research, from 'house' publications that include more society information than original research papers to large high-end journals that only include original research - and everything inbetween.

More recently, there has been a call for research information (particularly in the life sciences) to be made freely available through open access. Online journals have reduced the costs of production and delivery, although the cost of managing quality control (peer review and editorial office management) remains constant. For the authors, they have significantly shortened the time from acceptance to publication. Digitisation has also brought new journal models such as PLOS ONE to the forefront. These megajournals complement niche journals by providing online platforms for research, and accept a broad range of articles and topics. Articles that are methodologically correct are accepted but they may not have anything new to say.

Journals now frequently offer more than a publishing platform and invite researchers to become more engaged with the published research. Both the journal publishers and new technology-led companies are experimenting with adding further services for authors and readers, often built around access to journals, and include:

$>\quad$ social networks and file-sharing services for scientists

$>$ preprint servers

$>$ post-publication evaluation

$>$ data sharing

$>\quad$ text and data mining

$>$ mobile access and applications

\section{The role of journals for researchers}

The importance of journals in academic life goes beyond providing a means of communication and a permanent record. Journal articles are the final output of most research, and a researcher's performance and productivity are judged largely on the number of publications as well as where they appear. Journals have become deeply embedded in academic infrastructure. They are central to career paths, including both funding and appointments. Author surveys confirm that 'furthering my career' and 'future funding' are important motivations in publishing their work.

Journals are often selective and specialised in their coverage. As they compete for papers, their identity serves as a proxy for the research published there - and its significance. The impact factor (a measure of the citations to a particular journal) is frequently seen as the means of determining the importance of a journal, and is often used (and misused) by authors and academia to decide where to publish as well as how to rank the importance of a publication. A rigid and often misleading soundbite, the impact factor of a journal is akin to the term megapixel for digital cameras; the importance of a journal to a particular community is not always reflected in its impact factor. This is the subject of a later article in this series.

Authors may publish for a variety of reasons and the type of article can vary substantially. A journal is often perceived to comprise research articles but there are a wide variety of articles that serve the purpose of communication and provide valuable information to the community. News, editorials, letters, reviews, commentaries, images, audio clips and other forms of 'article' can be equally valuable to researchers, and can also be found in journals.

\section{The future of journals?}

In the mid-2000s Lee Dirks of Microsoft set out his vision for the future of research communication. This included:

$>$ Open access to both text and data will be the rule, not the exception.

$>\quad$ Publications will be live documents with links to (realtime) data and related software.

$>\quad$ New forms of peer review and social networking will be adopted.

$>$ Blogs and wikis for collaborative research will be normal operating procedure. 


\section{Key messages}

$>$ The basic function of a research journal is registration, certification, dissemination and archiving.

$>\quad$ The academic journal is still perceived as an important and robust method of publishing despite innovations in communication (blogs, monographs and other creative ways of communicating in the 21 st century).

$>350$ years after the first academic journal was published, there were 28,100 active scholarly peer reviewed journals in mid-2012, collectively publishing about 1.8-1.9 million articles a year.

$>\quad$ The number of articles published each year and the number of journals have both grown steadily for more than two centuries, by about $3 \%$ and $3.5 \%$ per year respectively.
$>$ Preservation and long-term access to datasets will be a mandated part of the scientific lifecycle.

$>\quad$ There will be a service industry around online data analysis, visualisation and dissemination of scientific information.

$>\quad$ Most of the above scenarios will be cloud-based services, hosted by third parties and not the academic institution.

It will be intriguing to see what accommodation the past and the visionary future will reach.

\section{Reference}

1. Ware M, Mabe M. The STM Report. 3rd edn. The Hague: International Association of Scientific, Technical and Medical Publishers; 2012.

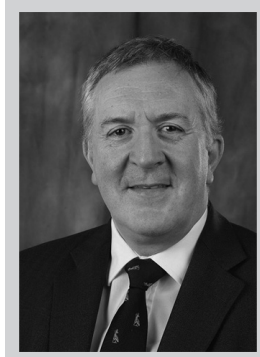

Coming up next time

In the second article in the publishing series, Professor Derek Alderson provides an excellent insight into 'What to publish?'. Professor Alderson is the Barling Professor of Surgery at the University of Birmingham and an honorary consultant surgeon at the Queen Elizabeth Hospital Birmingham. A Royal College of Surgeons Council member since 2008, he is chair of the Research Committee and is the current editor-in-chief of the British Journal of Surgery. 